Article

\title{
Improved Procedure for Earth Fault Loop Impedance Measurement in TN Low-Voltage Network
}

\author{
Liviu Neamt $^{1, *(\mathbb{D} \text {, Alina Neamt }}{ }^{2}$ and Olivian Chiver ${ }^{1}$ (D) \\ 1 Electrical, Electronic and Computer Engineering Department, Technical University of Cluj-Napoca, \\ 400114 Cluj-Napoca, Romania; olivian.chiver@cunbm.utcluj.ro \\ 2 “Anghel Saligny" Technical College, 430295 Baia Mare, Romania; alina23_tatiana@yahoo.com \\ * Correspondence: liviu.neamt@cunbm.utcluj.ro
}

check for

updates

Citation: Neamt, L.; Neamt, A.;

Chiver, O. Improved Procedure for Earth Fault Loop Impedance Measurement in TN Low-Voltage Network. Energies 2021, 14, 205. https://doi.org/10.3390/en14010205

Received: 26 November 2020 Accepted: 28 December 2020 Published: 2 January 2021

Publisher's Note: MDPI stays neutral with regard to jurisdictional clai$\mathrm{ms}$ in published maps and institutional affiliations.

Copyright: (C) 2021 by the authors. Licensee MDPI, Basel, Switzerland. This article is an open access article distributed under the terms and conditions of the Creative Commons Attribution (CC BY) license (https:// creativecommons.org/licenses/by/ $4.0 /)$.

\begin{abstract}
The difficulties and uncertainties related to earth fault loop impedance measurement are addressed in this paper. Based on the presentation of the measurement procedure implemented in the test equipment (diagrams and measured quantities, respectively, interpretation of results), the shortcomings and errors that accompany it are highlighted. The position in the power system, the influence of power transformers, and the use of effective quantities instead of phasors are important sources of errors, but, as will be seen, the switching of loads at the consumer sides and/or the occurrence of fault regimes during measurements can lead to the most serious impairment of the accuracy in the impedance assessment. The clarification of these aspects is achieved, both starting from the equivalent diagrams of the measurement circuits and the analytical interpretation of the phenomena associated with the measurements, as well as based on the modeling and simulation of TN low-voltage electrical distribution networks, in a specialized program, Eaton xSpider, which allows the complete and complex analysis of a large number of scenarios. Thus, essential conclusions were drawn regarding the level of errors and their causes, obviously, with the research coming with solutions to be implemented at the level of the measurement protocols of the devices used.
\end{abstract}

Keywords: electrical fault detection; electrical safety; power distribution; power grids

\section{Introduction}

The energy dependence of human society is indisputable. In the current context of the energy crisis and the problems related to global warming, electricity is the bridge to the new energy era of the planet. Due to the lack of accessible technology solutions for storing significant amounts of electricity, it is consumed simultaneously with production, which implies the need for the existence of power systems, the most complex and extensive man-made systems. Their exploitation must be safe and as simple as possible from the consumers' perspective. This desideratum is strongly dependent on the initial and periodic evaluations, through measurements and prophylactic tests to ensure the safety of the electrical installations.

This research deals with the above verifications in low-voltage distribution networks. The most common configuration of these networks is the TN, i.e., the grounded neutral (symbol T) and a network-driven protective earth connection (symbol N), either separately to the neutral conductor (TN-S) or combined with the neutral conductor (TN-C) or mixed (TN-C-S).

Generally, a TN low-voltage distribution network goes as TN-C on the transformer and distribution sides and, from the supplier-consumer delimitation point, it becomes TN-S (Figure 1). The $Z_{t 1}, Z_{t 2}$, and $Z_{t 3}$ are the phase transformer impedances, $Z_{d 1}, Z_{\mathrm{d} 2}$, and $Z_{d 3}$ are the phase impedances of the distribution line between transformer and supplierconsumer delimitation point, and $Z_{P E N}$ is the impedance of the common protective earth $(\mathrm{PE})$ and neutral $(\mathrm{N})$ conductor, with $Z_{N}$ and $Z_{P E}$ being the corresponding impedances of separate conductors $\mathrm{N}$ and PE. 


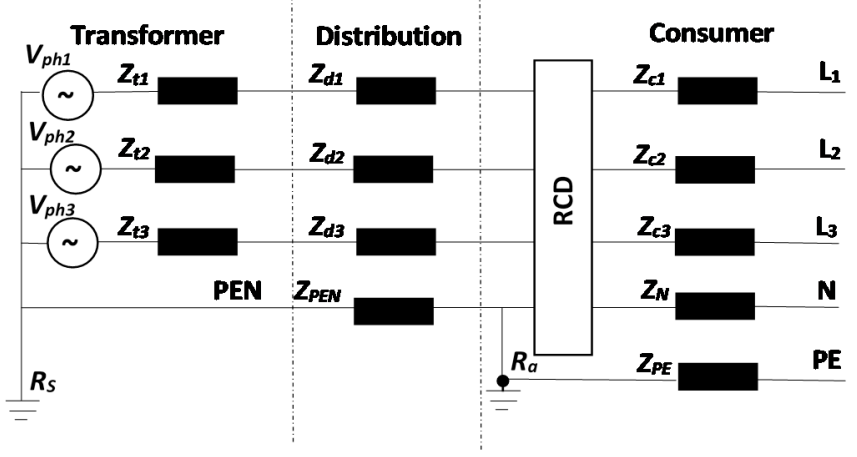

Figure 1. A TN-C-S network.

According to the standards in force, e.g., [1,2], in low-voltage electrical networks, one of the measurements that highlight the safety of electricity operation is the measurement of the earth fault loop impedance. Based on its values, the required disconnection times are correlated with the nominal voltage levels, of course, based on the tripping characteristics of the protection equipment and also it must prove that the touch voltage that may occur by an insulation failure will be below the allowable value.

The safe disconnection times for the TN low-voltage networks are presented in Table 1 [3], where $V_{p h}$ is the rated phase voltage.

Table 1. Safe disconnection time in TN low-voltage network.

\begin{tabular}{cc}
\hline Rated Phase Voltage $V_{\boldsymbol{p h}}$ Range (V) & Safe Disconnection Time (s) \\
\hline$(50 ; 120]$ & 0.8 \\
$(120 ; 230]$ & 0.4 \\
$(230 ; 400]$ & 0.2 \\
$>400$ & 0.1 \\
\hline
\end{tabular}

To reach these tripping times, the following condition must be met:

$$
Z_{\text {loop }} \cdot I_{a} \leq V_{\text {ph }}
$$

where $Z_{\text {loop }}$ is the earth fault loop impedance and $I_{a}$ is the tripping current for safe disconnection time.

It becomes easier to treat (1) as:

$$
Z_{\text {loop }} \leq \frac{V_{p h}}{I_{a}}=Z_{\text {loopMAX }}
$$

$Z_{\text {loopMAX }}$ is the result of analyzing the tripping characteristics of the usual protective equipment. According to [4], in TN low-voltage distribution network equipped with protective devices, circuit breaker $(\mathrm{CB})$ or general-purpose fuse $(\mathrm{gG})$, the maximum measured values of earth fault loop impedance should not exceed the values specified in Table 2 when the conductors are at their normal operating temperature (e.g., $70{ }^{\circ} \mathrm{C}$ for thermoplastic insulated conductors).

Due to the difficulty of assessing the temperature of the electrical network at the time of measurement, [3] recommends considering the worst-case scenario, i.e., under no-load condition measurement, at a low temperature, and in interpreting the inequality (2) (see the corresponding values in Table 2).

The earth fault loop impedance measurement method, implemented in most testers, is based on the simplified equivalent scheme, shown in Figure 2 [4], in which the voltages are measured between the live and PE (earth) conductors, through a known resistor, Ri, or in no-load (from points a and $\mathrm{b}$ perspective) condition. 
Table 2. Maximum measured values of the earth fault loop impedance at normal and at the unknown operating temperature.

\begin{tabular}{|c|c|c|c|c|c|c|}
\hline \multirow{3}{*}{$\begin{array}{l}\text { Rated Current } \\
\text { (A) }\end{array}$} & \multicolumn{6}{|c|}{$Z_{\text {loopMAX }}(\Omega)$} \\
\hline & \multicolumn{2}{|c|}{ CB Type B } & \multicolumn{2}{|c|}{ CB Type C } & \multicolumn{2}{|c|}{ gG Fuse } \\
\hline & $\begin{array}{c}\text { Normal } \\
\text { Operating } \\
\text { Temperature }\end{array}$ & $\begin{array}{c}\text { Unknown } \\
\text { Operating } \\
\text { Temperature }\end{array}$ & $\begin{array}{c}\text { Normal } \\
\text { Operating } \\
\text { Temperature }\end{array}$ & $\begin{array}{c}\text { Unknown } \\
\text { Operating } \\
\text { Temperature }\end{array}$ & $\begin{array}{c}\text { Normal } \\
\text { Operating } \\
\text { Temperature }\end{array}$ & $\begin{array}{c}\text { Unknown } \\
\text { Operating } \\
\text { Temperature }\end{array}$ \\
\hline 10 & 4.37 & 3.50 & 2.18 & 1.74 & 4.85 & 3.88 \\
\hline 16 & 2.72 & 2.18 & 1.35 & 1.08 & 2.56 & 2.05 \\
\hline 25 & 1.74 & 1.39 & 0.86 & 0.69 & 1.35 & 1.08 \\
\hline 32 & 1.35 & 1.08 & 0.68 & 0.54 & 0.99 & 0.79 \\
\hline 63 & 0.69 & 0.55 & 0.34 & 0.27 & 0.425 & 0.34 \\
\hline 100 & 0.43 & 0.34 & 0.2 & 0.16 & 0.21 & 0.17 \\
\hline
\end{tabular}

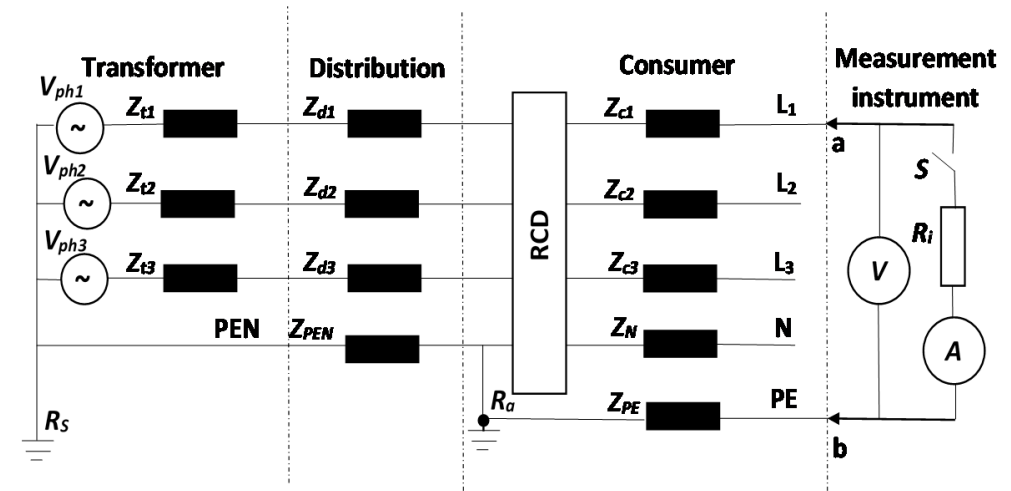

Figure 2. Simplified equivalent circuit during earth fault loop impedance measurement.

Consequently, the earth fault loop impedance results as the sum of the impedances of the network components, namely:

$$
\underline{Z}_{\text {loop }}=\underline{Z}_{t 1}+\underline{Z}_{d 1}+\underline{Z}_{c 1}+\underline{Z}_{P E}+\underline{Z}_{P E N}
$$

where $Z_{c 1}$ is the phase impedance of the line between the supplier-consumer delimitation point and the measurement point $\mathbf{a}$.

The tester measures the rms voltage $V_{\text {open }}$ with the switch $\mathbf{S}$ open and the rms voltage $V_{\text {closeds }}$ with the switch $\mathbf{S}$ closed. Because the internal resistance $R_{i}$ of the device is known, the current $I$ flowing through it can be determined or, alternatively, by measuring the current, the voltage $V_{\text {closeds }}$ can be deduced:

$$
\begin{gathered}
V_{\text {closed }}=I \cdot R_{i} \Rightarrow I=\frac{V_{\text {closed }}}{R_{i}} \\
V_{\text {closed }}=V_{\text {ph } 1}-I \cdot Z_{\text {loop }} \\
V_{\text {opens }}=V_{\text {ph } 1}=I \cdot\left(R_{i}+Z_{\text {loop }}\right)=\frac{V_{\text {closed }}}{R_{i}} \cdot\left(R_{i}+Z_{\text {loop }}\right)
\end{gathered}
$$

Finally, based on the measurement of two variables, $V_{\text {opens }}$ and $I$ or $V_{\text {open }}$ and $V_{\text {closedS }}$, the earth fault loop impedance is depicted as:

$$
Z_{\text {loop }}=\frac{V_{\text {opens }}}{I}-R_{i}=R_{i} \cdot\left(\frac{V_{\text {opens }}-V_{\text {closed }}}{V_{\text {closed }}}\right) .
$$




\section{Source of Errors}

The result of determining the loop impedance, according to the above algorithm, is an approximate one. The first error that occurs is related to the operation with effective quantities instead of the phasors [4-12]. The correct value of the loop impedance would be:

$$
\underline{Z}_{\text {loop }}=\frac{\underline{V}_{\text {openS }}}{\underline{I}}-R_{i}=R_{i} \cdot\left(\frac{\underline{V}_{\text {openS }}-\underline{V}_{\text {closed }}}{\underline{V}_{\text {closed }}}\right),
$$

and

$$
Z_{\text {loop }}=\left|\frac{\underline{V}_{\text {openS }}}{\underline{I}}-R_{i}\right|=\left|R_{i} \cdot\left(\frac{\underline{V}_{\text {openS }}-\underline{V}_{\text {closed }}}{\underline{V}_{\text {closed }}}\right)\right|,
$$

With $\underline{V}_{\text {openS }}, \underline{I}$ and $\underline{V}_{\text {closed }}$ being the phasors of the voltages and current involved in fault loop impedance measurement.

In low-voltage distribution networks, the inductive and capacitive reactance generally have low values, the important exception being the inductive reactance of the transformer. Thus, if the measurement of the loop impedance takes place at a point of the network away (electrically) from the transformer, then the error will be significantly reduced.

Moreover, the presence of other consumers in the distribution network is not quantified, i.e., the simplified equivalent circuit during earth fault loop impedance measurement generates errors. The complete circuit is shown in Figure 3 (the switch $\mathbf{S}$ is shown closed to illustrate the current flow in the network), where all consumers are reduced to an equivalent one, placed at the end of an equivalent distribution network. It is obvious that for no other consumer connected to the distribution network, except the one denoted simply consumer, at which the loop impedance test is performed, the complete circuit is equivalent to the simplified one.

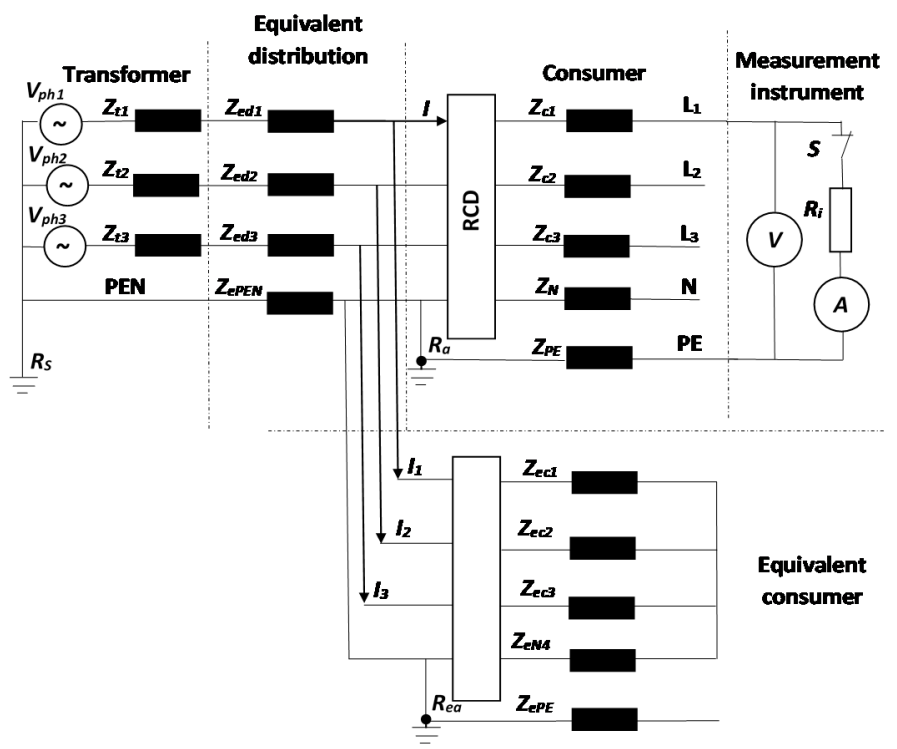

Figure 3. Complete equivalent circuit during earth fault loop impedance measurement.

The $Z_{t 1}, Z_{t 2}$, and $Z_{t 3}$ are the phase transformer impedances. $Z_{e d 1}, Z_{e d 2}$, and $Z_{e d 3}$ are the phase impedances of the equivalent distribution line between transformer and supplier-consumer delimitation point. $Z_{e P E N}$ is the impedance of the equivalent PEN conductor. $Z_{c 1}, Z_{c 2}$, and $Z_{c 3}$ are the phase impedances of the line between the supplierconsumer delimitation point and the measurement point. $Z_{N}$ and $Z_{P E}$ are the corresponding impedances of separate conductors $\mathrm{n}$ and PE in consumer installation and, finally, $Z_{e c 1}$, $Z_{e c 2}, Z_{e c 3}, Z_{e N}$, and $Z_{e P E}$ are the equivalent consumer impedances. 
The potential source of error coming from other connected consumer is revealed in the following Equations:

$$
\begin{gathered}
\underline{V}_{\text {closeds }}=\underline{I} \cdot R_{i} \Rightarrow \underline{I}=\frac{\underline{V}_{c l o s e d S}}{R_{i}} \\
\underline{V}_{\text {closed }}=\underline{V}_{p h 1}-\left(\underline{I}_{1}+\underline{I}_{1}\right) \cdot\left(\underline{Z}_{t 1}+\underline{Z}_{e d 1}\right)-\underline{I}^{\prime} \cdot\left(\underline{Z}_{c 1}+\underline{Z}_{P E}\right)-\left(\underline{I}_{1}+\underline{I}_{2}+\underline{I}_{3}+\underline{I}\right) \cdot \underline{Z}_{e P E N} \\
\underline{V}_{\text {opens }}=\underline{V}_{p h 1}-\underline{I}_{1} \cdot\left(\underline{Z}_{t 1}+\underline{Z}_{e d 1}\right)-\left(\underline{I}_{1}+\underline{I}_{2}+\underline{I}_{3}\right) \cdot \underline{Z}_{e P E N}
\end{gathered}
$$

Rearranging (11) as:

$$
\begin{aligned}
& \underline{V}_{\text {closeds }}=\underline{V}_{p h 1}-\underline{I}_{1} \cdot\left(\underline{Z}_{t 1}+\underline{Z}_{e d 1}\right)-\left(\underline{I}_{1}+\underline{I}_{2}+\underline{I}_{3}\right) \cdot \underline{Z}_{e P E N}-\underline{I} \cdot\left(\underline{Z}_{t 1}+\underline{Z}_{e d 1}+\underline{Z}_{c 1}+\underline{Z}_{P E}+\underline{Z}_{e P E N}\right) \\
& \quad \text { and (12) as: }
\end{aligned}
$$

$$
\underline{V}_{o p e n S}-\underline{V}_{p h 1}=-\underline{I}_{1} \cdot\left(\underline{Z}_{t 1}+\underline{Z}_{e d 1}\right)-\left(\underline{I}_{1}+\underline{I}_{2}+\underline{I}_{3}\right) \cdot \underline{Z}_{e P E N}
$$

it can be written:

$$
\underline{V}_{\text {closeds }}=\underline{V}_{\text {opens }}-\underline{I} \cdot \underline{Z}_{\text {loop }}
$$

Apparently, other consumers do not influence earth loop impedance measurement, but relation (14) is a consequence of (10) to (12) only if the circuit is not modified during the measurement. That is, if the currents $I_{1}, I_{2}$, or $I_{3}$ change by connecting/disconnecting some loads of any consumer powered by the analyzed network or, even worse, if fault regimes occur (overcurrents or under/overvoltages) exactly when switch $\mathbf{S}$ changes state, the relationship (14) is no longer correct, i.e., the Equations (11) and (12) are written as:

$$
\begin{gathered}
\underline{V}_{\text {closedS }}=\underline{V}_{p h 1}-\left(\underline{I}+\underline{I}_{1}\right) \cdot\left(\underline{Z}_{t 1}+\underline{Z}_{e d 1}\right)-\underline{I} \cdot\left(\underline{Z}_{c 1}+\underline{Z}_{P E}\right)-\left(\underline{I}_{1}+\underline{I}_{2}+\underline{I}_{3}+\underline{I}\right) \cdot \underline{Z}_{e P E N} \\
\underline{V}_{\text {openS }}=\underline{V}_{p h 1}^{\prime}-\underline{I}^{\prime}{ }_{1} \cdot\left(\underline{Z}_{t 1}+\underline{Z}_{e d 1}\right)-\left(\underline{I}_{1}^{\prime}+\underline{I}^{\prime}{ }_{2}+\underline{I}^{\prime}{ }_{3}\right) \cdot \underline{Z}_{e P E N}
\end{gathered}
$$

with:

$$
\underline{I}_{1} \neq \underline{I}_{1}^{\prime} \text { or } / \text { and } \underline{I}_{2} \neq \underline{I}_{2}^{\prime} \text { or } / \text { and } \underline{I}_{3} \neq \underline{I}_{3}^{\prime} \text { or } / \text { and } \underline{V}_{p h 1}=\underline{V}_{p h 1}^{\prime}
$$

meaning that (15) could not be reached anymore.

\section{Suggested Procedure}

Analyzing the sources of errors, we can suggest an improved procedure to perform the earth fault loop testing.

Due to the technical and financial implication we divided the procedure into two available solutions:

- To rule out problems associated with loads switching at the consumer's side, or the influence of defect regimes, the next protocol of measurements must be applied: Repetitive measurement of the voltages: $V_{\text {closedS }}, V_{\text {openS }}, V_{\text {closedS }}, \ldots V_{\text {openS }}, V_{\text {closed }}$ until the values of the voltage $V_{\text {closed }}$ of two successive measurements is the same (obviously within the limits of an imposed error).

- To avoid the error associated with the effects of measurement and calculations with effective quantities instead of phasors, the two required variables, $V_{\text {opens }}$ and $I$ or $V_{\text {open }}$ and $V_{\text {closedS }}$, must be measured as rms values but also the phase shift between them must be recorded.

\section{Validation}

For validation, a low-voltage TN distribution network was analyzed in several configurations and operating modes. For faster computation, a dedicated graphically oriented design system for dimensioning and calculation of low-voltage networks, xSpider [13] developed by Eaton, was used.

First, we considered an ideal network consisting of purely resistive elements to highlight the influence of consumer switching on the distribution network during the mea- 
surement of the fault loop impedance (Figure 4). Please note that the commutation and protective equipment are not represented.

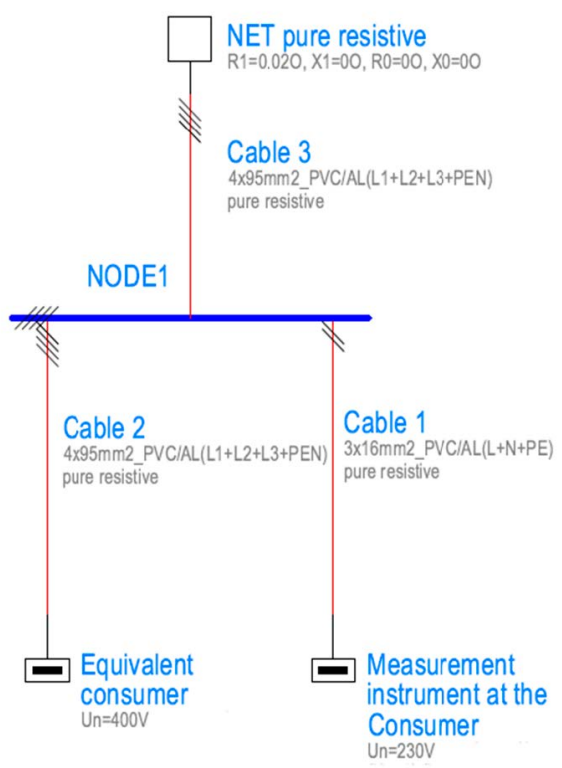

Figure 4. Purely resistive network.

The equivalent consumer was considered with different powers and the measurement instrument in the "closed S" regime was simulated by introducing a 2.3-kW resistive load. "Cable 1 " is the consumer line between the supplier-consumer delimitation point, "NODE 1 ", and the measurement point. In other words, "Cable 1" and "Measurement instrument at the Consumer" from Figure 4 are "Consumer" and "Measurement instrument" from Figure 3.

XSpider uses for calculation two algorithms: one omitting the impact of the voltage drop and the other one taking into account the impact of the voltage drop, i.e., either the load currents are constant or the load outputs are constant [13].

"Cable 2" and "Equivalent consumer" from Figure 4 are "Equivalent consumer" from Figure 3. "NET" and "Cable 3" from Figure 4 cover the "Transformer" and "Equivalent distribution" sections from Figure 3.

Using "the constant load current", we can obtain the earth fault loop impedance, from (6), as:

$$
Z_{\text {loop }}=\frac{V_{\text {opens }}-V_{\text {closed }}}{I}
$$

The equivalent power supply, "NET pure resistive", has the active positive-sequence network resistance, $R_{1}=0.02 \Omega$.

Cables 2 and 3, length $1 \mathrm{~m}$ and $500 \mathrm{~m}$, respectively, are $4 \times 95 \mathrm{~mm}^{2}$ polyvinyl chloride $(\mathrm{PVC})$ insulated aluminum conductor cables, installed in air with the specific positivesequence network resistance, $\mathrm{r}_{1}=0.326 \mathrm{~m} \Omega / \mathrm{m}$, and the specific active zero-sequence network resistance, $\mathrm{r}_{0}=1 \mathrm{~m} \Omega / \mathrm{m}$. Of course, both specific inductive reactances, positivesequence network $\mathrm{x}_{1}$ and zero-sequence network $\mathrm{x}_{0}$, are zero.

Cable 1 is also a PVC insulated aluminum conductor cable, but $4 \times 16 \mathrm{~mm}^{2}$ having $\mathrm{r}_{1}=1.935 \mathrm{~m} \Omega / \mathrm{m}$ and $\mathrm{r}_{0}=7.74 \mathrm{~m} \Omega / \mathrm{m}, \mathrm{x}_{1}=\mathrm{x}_{0}=0$.

In Table 3 are presented the simulation results and interpretations for earth fault loop impedance measurement based on (7).

In a purely resistive network, the earth fault loop impedance presents no error in the measurement procedure compared with the computed one. This statement is true if $V_{\text {opens }}$ and $V_{\text {closeds }}$ refer to the same current circulation. If, for example, the testing instrument measures a value of $V_{\text {closeds }}=224.204 \mathrm{~V}$, which is the value for a $5-\mathrm{kW}$ equivalent consumer connected, and a value of 229.977 for $V_{\text {opens }}$, corresponding to no equivalent consumer, the 
error between measured and real values of the $Z_{\text {loop }}$ is $32.1 \%$. The above results could have arrived if, during the measurements, the 5-kW load is disconnected.

Table 3. Purely resistive network.

\begin{tabular}{|c|c|c|c|c|c|}
\hline \multicolumn{2}{|c|}{ Equivalent Consumer } & \multicolumn{3}{|c|}{$\begin{array}{l}\text { Measurement Instrument } \\
\text { Based on (7) }\end{array}$} & \multirow{2}{*}{$\begin{array}{c}Z_{\text {loop }}(\Omega) \\
\text { Accurate Value }\end{array}$} \\
\hline$p(\mathbf{k W})$ & $\cos \varphi$ & $V_{\text {opens }}(\mathrm{V})$ & $V_{\text {closeds }}(\mathrm{V})$ & $Z_{\text {loop }}(\Omega)$ & \\
\hline 0 & \multirow{4}{*}{1} & 229.977 & 225.607 & 0.437 & \multirow{4}{*}{0.437} \\
\hline 5 & & 228.574 & 224.204 & 0.437 & \\
\hline 10 & & 227.171 & 222.801 & 0.437 & \\
\hline 100 & & 201.733 & 197.363 & 0.437 & \\
\hline
\end{tabular}

Taking, for example, the extreme values illustrated in Table 4 , the error reaches 646.32\%:

$$
\begin{gathered}
Z_{\text {loopmeasured }}=\frac{229.977 \mathrm{~V}-197.363 \mathrm{~V}}{10 \mathrm{~A}}=3.2614 \Omega \\
\varepsilon=\frac{Z_{\text {loopmeasured }}-Z_{\text {loopaccurate }}}{Z_{\text {loopaccurate }}} \cdot 100=646.32 \%
\end{gathered}
$$

\begin{tabular}{|c|c|}
\hline Component & Parameter \\
\hline NET & Short-circuit power (3-phase short-circuit), $S_{k 3 p}=300$ MVA \\
\hline \multirow[t]{2}{*}{ TR1 } & $\begin{array}{c}\text { Rated power } S_{r}=100 \mathrm{kVA}, 22 / 0.4 \mathrm{kV}, \mathrm{Yz}_{\mathrm{n} 1} \\
\text { Short-circuit losses } \mathrm{P}_{\mathrm{k}}=2.15 \mathrm{~kW} \text {, Short-circuit voltage } \mathrm{u}_{\mathrm{k}}=4 \% \\
\text { and }\end{array}$ \\
\hline & $\begin{array}{c}\text { Rated power } S_{r}=400 \mathrm{kVA}, 22 / 0.4 \mathrm{kV}, \mathrm{Dy} \mathrm{y}_{1} \\
\text { Short-circuit losses } \mathrm{P}_{\mathrm{k}}=6.265 \mathrm{~kW} \text {, Short-circuit voltage } \mathrm{u}_{\mathrm{k}}=6 \%\end{array}$ \\
\hline Cable 1 & $\begin{array}{c}\mathrm{r}_{1}=1.935 \mathrm{~m} \Omega / \mathrm{m}, \mathrm{r}_{0}=7.74 \mathrm{~m} \Omega / \mathrm{m}, \mathrm{x}_{1}=0.082 \mathrm{~m} \Omega / \mathrm{m}, \mathrm{x}_{0}=0.2952 \mathrm{~m} \Omega / \mathrm{m}, \\
\mathrm{L}=10 \mathrm{~m}\end{array}$ \\
\hline Cable 2 & $\begin{array}{c}\mathrm{r}_{1}=0.326 \mathrm{~m} \Omega / \mathrm{m}, \mathrm{r}_{0}=1.586618 \mathrm{~m} \Omega / \mathrm{m}, \mathrm{x}_{1}=0.082 \mathrm{~m} \Omega / \mathrm{m} \\
\mathrm{x}_{0}=0.2952 \mathrm{~m} \Omega / \mathrm{m}, \mathrm{L}=1 \mathrm{~m}\end{array}$ \\
\hline Cable 3 & $\begin{array}{c}\mathrm{r}_{1}=0.326 \mathrm{~m} \Omega / \mathrm{m}, \mathrm{r}_{0}=1.58618 \mathrm{~m} \Omega / \mathrm{m}, \mathrm{x}_{1}=0.082 \mathrm{~m} \Omega / \mathrm{m} \\
\mathrm{x}_{0}=0.2952 \mathrm{~m} \Omega / \mathrm{m}, \mathrm{L}=10 \div 500 \mathrm{~m}\end{array}$ \\
\hline Equivalent consumer & $P_{\mathrm{n}}=0 ; 5 ; 10$ and $100 \mathrm{~kW}, \cos \varphi=0.5 ; 0.75$ and 1 \\
\hline Measurement instrument & $P_{n}=0$ and $2.3 \mathrm{~kW}$ \\
\hline
\end{tabular}

Table 4. Purely resistive network.

If the algorithm for repetitive voltage measurement with switch $\mathbf{S}$ of the device closed, open, ..., closed is implemented, this error can be avoided.

To quantify the error level associated with the effects of measurement and calculations with effective quantities instead of phasors, a typical low-voltage distribution network is considered (Figure 5).

The network component parameters are depicted in Table 4.

The simulation results of the above networks, along with the earth fault loop impedances determined based on (7), and the accurate values are presented in Tables 5-8. 


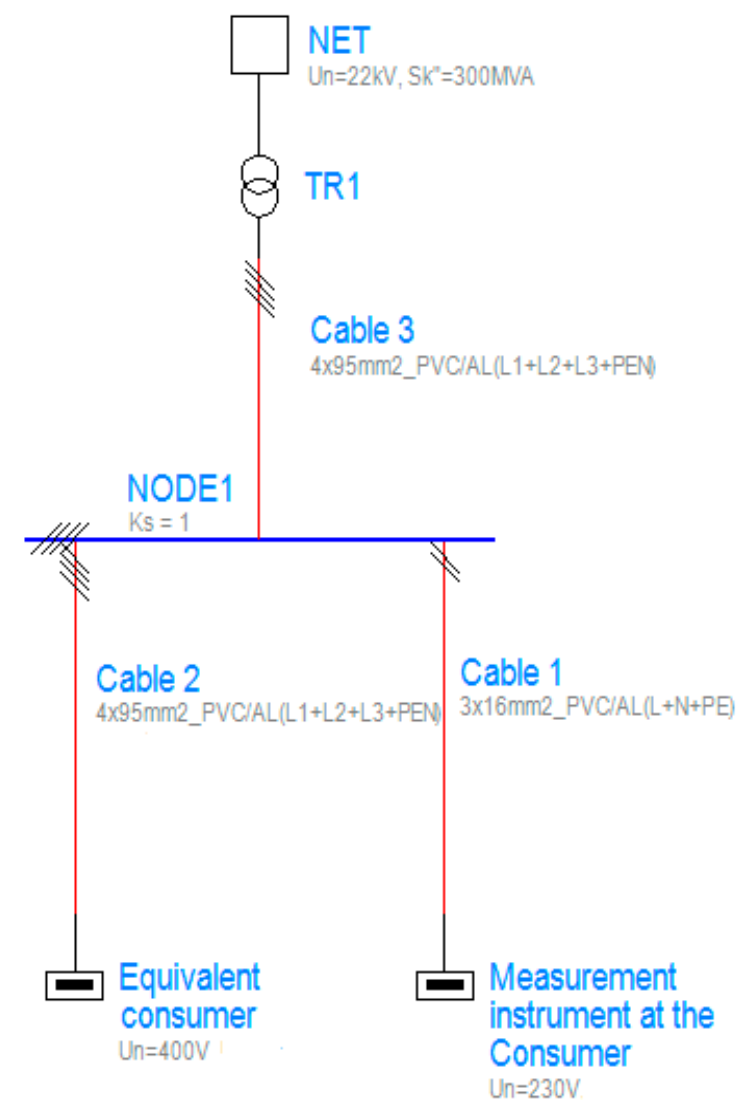

Figure 5. Typical low-voltage distribution network.

Table 5. The 100-kVA transformer and $L=10 \mathrm{~m}$ for cable 3 .

\begin{tabular}{|c|c|c|c|c|c|}
\hline \multicolumn{2}{|c|}{ Equivalent Consumer } & \multicolumn{3}{|c|}{$\begin{array}{l}\text { Measurement Instrument } \\
\text { Based on (7) }\end{array}$} & \multirow{2}{*}{$\begin{array}{c}\mathrm{Z}_{\text {loop }}(\Omega) \\
\text { Accurate Value }\end{array}$} \\
\hline$p(\mathrm{~kW})$ & $\cos \varphi$ & $V_{\text {opens }}(\mathrm{V})$ & $V_{\text {closedS }}(\mathrm{V})$ & $Z_{\text {loop }}(\Omega)$ & \\
\hline 0 & \multirow{4}{*}{1} & 230.000 & 229.448 & 0.0552 & \multirow{12}{*}{$0.0845=|0.0725+\mathrm{j} \cdot 0.0425|$} \\
\hline 5 & & 229.977 & 229.425 & 0.0552 & \\
\hline 10 & & 229.954 & 229.402 & 0.0552 & \\
\hline 100 & & 229.448 & 228.896 & 0.0552 & \\
\hline 0 & \multirow{4}{*}{0.75} & 230.000 & 229.448 & 0.0552 & \\
\hline 5 & & 229.977 & 229.425 & 0.0552 & \\
\hline 10 & & 229.931 & 229.379 & 0.0552 & \\
\hline 100 & & 229.333 & 228.781 & 0.0552 & \\
\hline 0 & \multirow{4}{*}{0.5} & 230.000 & 229.448 & 0.0552 & \\
\hline 5 & & 229.977 & 229.425 & 0.0552 & \\
\hline 10 & & 229.931 & 229.379 & 0.0552 & \\
\hline 100 & & 229.241 & 228.689 & 0.0552 & \\
\hline
\end{tabular}


Table 6. The 100-kVA transformer and $L=500 \mathrm{~m}$ for cable 3 .

\begin{tabular}{|c|c|c|c|c|c|}
\hline \multicolumn{2}{|c|}{ Equivalent Consumer } & \multicolumn{3}{|c|}{$\begin{array}{l}\text { Measurement Instrument } \\
\text { Based on (7) }\end{array}$} & \multirow{2}{*}{$\begin{array}{c}Z_{\text {loop }}(\Omega) \\
\text { Accurate Value }\end{array}$} \\
\hline$p(\mathbf{k W})$ & $\cos \varphi$ & $V_{\text {opens }}(\mathrm{V})$ & $V_{\text {closeds }}(\mathrm{V})$ & $Z_{\text {loop }}(\Omega)$ & \\
\hline 0 & \multirow{4}{*}{1} & 229.977 & 225.607 & 0.437 & \multirow{12}{*}{$0.464=|0.449+j \cdot 0.1175|$} \\
\hline 5 & & 228.574 & 224.204 & 0.437 & \\
\hline 10 & & 227.171 & 222.801 & 0.437 & \\
\hline 100 & & 201.756 & 197.386 & 0.437 & \\
\hline 0 & \multirow{4}{*}{0.75} & 229.977 & 225.607 & 0.437 & \\
\hline 5 & & 228.321 & 223.951 & 0.437 & \\
\hline 10 & & 226.642 & 222.272 & 0.437 & \\
\hline 100 & & 197.386 & 193.016 & 0.437 & \\
\hline 0 & \multirow{4}{*}{0.5} & 229.977 & 225.607 & 0.437 & \\
\hline 5 & & 228.068 & 223.698 & 0.437 & \\
\hline 10 & & 226.159 & 221.789 & 0.437 & \\
\hline 100 & & 196.190 & 191.820 & 0.437 & \\
\hline
\end{tabular}

Table 7. The 400-kVA transformer and $L=10 \mathrm{~m}$ for cable 3.

\begin{tabular}{|c|c|c|c|c|c|}
\hline \multicolumn{2}{|c|}{ Equivalent Consumer } & \multicolumn{3}{|c|}{$\begin{array}{c}\text { Measurement Instrument } \\
\text { Based on (7) }\end{array}$} & \multirow{2}{*}{$\begin{array}{c}Z_{\text {loop }}(\Omega) \\
\text { Accurate Value }\end{array}$} \\
\hline$p(\mathrm{~kW})$ & $\cos \varphi$ & $V_{\text {opens }}(\mathrm{V})$ & $V_{\text {closeds }}(\mathrm{V})$ & $Z_{\text {loop }}(\Omega)$ & \\
\hline 0 & \multirow{4}{*}{1} & 230.000 & 229.448 & 0.0552 & \multirow{12}{*}{$0.0585=|0.0 .053+j \cdot 0.0235|$} \\
\hline 5 & & 229.977 & 229.425 & 0.0552 & \\
\hline 10 & & 229.954 & 229.402 & 0.0552 & \\
\hline 100 & & 229.448 & 228.896 & 0.0552 & \\
\hline 0 & \multirow{4}{*}{0.75} & 230.000 & 229.448 & 0.0552 & \\
\hline 5 & & 229.977 & 229.425 & 0.0552 & \\
\hline 10 & & 229.931 & 229.379 & 0.0552 & \\
\hline 100 & & 229.333 & 228.781 & 0.0552 & \\
\hline 0 & \multirow{4}{*}{0.5} & 230.000 & 229.448 & 0.0552 & \\
\hline 5 & & 229.977 & 229.425 & 0.0552 & \\
\hline 10 & & 229.931 & 229.379 & 0.0552 & \\
\hline 100 & & 229.241 & 228.689 & 0.0552 & \\
\hline
\end{tabular}

It is visible that, not taking into account the switching of some loads during the loop impedance measurement, the errors increased over $30 \%$, maximum allowable error $[1,2]$, only in the case of networks fed by low-power transformers and for measuring points close to it. See the network with 100-kVA transformer and $\mathrm{L}=10 \mathrm{~m}$ for cable 3 .

If the errors determined by the use of the effective quantities instead of the phasors overlap those generated by the switching of the various loads between the moments of the voltage measurement, the cumulated values can exceed $700 \%$. For example, for a distribution network with a 400-kVA transformer and a cable 3 length of $500 \mathrm{~m}$, this error, 
if the measurement of $V_{\text {openS }}$ and $V_{\text {closed }}$ are performed with no load, respectively, with $100 \mathrm{~kW}$ and $\cos \varphi=0.5$ connected, could achieve the next value:

$$
\begin{aligned}
& Z_{\text {loopmeasured }}=\frac{229.977 \mathrm{~V}-191.82 \mathrm{~V}}{10 \mathrm{~A}}=3.8157 \Omega \\
& \varepsilon=\frac{Z_{\text {loopmeasured }}-Z_{\text {loopaccurate }}}{Z_{\text {loopaccurate }}} \cdot 100=765.24 \% .
\end{aligned}
$$

\begin{tabular}{|c|c|c|c|c|c|}
\hline \multicolumn{2}{|c|}{ Equivalent Consumer } & \multicolumn{3}{|c|}{$\begin{array}{l}\text { Measurement Instrument } \\
\text { Based on (7) }\end{array}$} & \multirow{2}{*}{$\begin{array}{c}Z_{\text {loop }}(\Omega) \\
\text { Accurate Value }\end{array}$} \\
\hline$p(\mathrm{~kW})$ & $\cos \varphi$ & $V_{\text {openS }}(\mathrm{V})$ & $V_{\text {closedS }}(\mathrm{V})$ & $Z_{\text {loop }}(\Omega)$ & \\
\hline 0 & \multirow{4}{*}{1} & 229.977 & 225.607 & 0.437 & \multirow{12}{*}{$0.441=|0.4295+j \cdot 0.05|$} \\
\hline 5 & & 228.574 & 224.204 & 0.437 & \\
\hline 10 & & 227.171 & 222.801 & 0.437 & \\
\hline 100 & & 201.756 & 197.386 & 0.437 & \\
\hline 0 & \multirow{4}{*}{0.75} & 229.977 & 225.607 & 0.437 & \\
\hline 5 & & 228.321 & 223.951 & 0.437 & \\
\hline 10 & & 226.642 & 222.272 & 0.437 & \\
\hline 100 & & 197.386 & 193.016 & 0.437 & \\
\hline 0 & \multirow{4}{*}{0.5} & 229.977 & 225.607 & 0.437 & \\
\hline 5 & & 228.068 & 223.698 & 0.437 & \\
\hline 10 & & 226.159 & 221.789 & 0.437 & \\
\hline 100 & & 196.190 & 191.820 & 0.437 & \\
\hline
\end{tabular}

Table 8. The 400-kVA transformer and $L=500 \mathrm{~m}$ for cable 3 .

\section{Conclusions}

The sources of errors that occur when measuring the loop impedance in a TN distribution network are:

- The switching of loads at the consumer sides and/or the occurrence of fault regimes during measurements and

- The use of effective quantities instead of phasors, which becomes significant if the inductive reactance of the network components becomes comparable to their resistance.

To minimize these errors, based on the presented results, two essential aspects can be clearly distinguished in terms of fault loop impedance measurement:

- The next protocol must be applied: repetitive measurement of the voltages, $V_{\text {closed }}$, $V_{\text {openS }}, V_{\text {closedS }}, \ldots V_{\text {openS }}, V_{\text {closeds }}$, until the values of the voltage $V_{\text {closeds }}$ of two successive measurements is the same (obviously within the limits of an imposed error). This first rule is mandatory because it avoids the huge errors that occur due to the switching of the loads during the measurement and, also, it is simple and cheap to implement in the measuring equipment.

- To avoid the error associated with the effects of measurement and calculations with effective quantities instead of phasors, the two required variables, $V_{\text {opens }}$ and $I$ or $V_{\text {opens }}$ and $V_{\text {closedS }}$, must be measured as rms values but also the phase shift between them must be recorded. As seen in those presented in the paper, errors of over $30 \%$ occur in measurements near distribution transformers if they have low-rated powers. As the cost of implementing such an algorithm is higher, the solution may be unjustifiable at the usual measurements, i.e., far from the power transformers. Another comment has to be made here: We used a two-wire, high-current testing 
method [14] for analyzing measurement apparatus, but with a two- or three-wire "no trip" algorithm implemented [14], the errors will be greater than those presented here due to the external influences and the need for increased voltage measurement accuracy. In this case, using phasors can be reconsidered.

In summary, measuring the impedances of the fault loops is a rather complex process and can be accompanied by significant errors. On the other hand, the interpretations that can be obtained, based on the measurements of the mentioned impedance being very important regarding the safety of the power system operation, fully justify the need to improve the methodology implemented in the measuring devices.

Author Contributions: Conceptualization, L.N., A.N., and O.C.; methodology, L.N.; validation, L.N., A.N., and O.C.; writing-original draft preparation, L.N.; writing-review and editing, L.N. All authors have read and agreed to the published version of the manuscript.

Funding: This research received no external funding.

Institutional Review Board Statement: Not applicable.

Informed Consent Statement: Not applicable.

Data Availability Statement: The data presented in this study are fully available in the body of the paper.

Conflicts of Interest: The authors declare no conflict of interest.

\section{References}

1. Low-Voltage Electrical Installations_Part 6: Verification; HD 60364-6; IEC: Geneva, Switzerland, 2016.

2. Electrical Safety in Low Voltage Distribution Systems up to $1000 \mathrm{~V}$ a.c. and $1500 \mathrm{~V}$ d.c. Equipment for Testing, Measuring or Monitoring of Protective Measures; EN 61557; IEC: Geneva, Switzerland, 2007-2008.

3. Low-Voltage Electrical Installations-Part 4-41: Protection for Safety-Protection against Electric Shock; IEC 60364-4-41; IEC: Geneva, Switzerland, 2012.

4. Neamt, L.; Balan, H.; Chiver, O.; Hotea, A. Considerations about Fault Loop Impedance Measurement in TN Low-Voltage Network. In Proceedings of the 8th International Conference on Modern Power Systems (MPS), Cluj Napoca, Romania, 21-23 May 2019; pp. 1-4.

5. Roskosz, R.; Musial, E.; Czapp, S. A method of earth fault loop impedance measurement without unwanted tripping of RCDs. In Proceedings of the Progress in Applied Electrical Engineering (PAEE), Koscielisko, Poland, 18-22 June 2018; pp. 1-4.

6. Mitolo, M.; Bajzek, T.J. Measuring the electrical safety in low-voltage distribution systems. In Proceedings of the IEEE/IAS 54th Industrial and Commercial Power Systems Technical Conference (I\&CPS), Niagara Falls, ON, Canada, 7-10 May 2018; pp. 1-4.

7. Liu, H.; Mitolo, M.; Qiu, J. Ground-Fault Loop Impedance Calculations in Low-Voltage Single-Phase Systems. IEEE Trans. Ind. Applic. 2014, 50, 1331-1337.

8. Czapp, S. Fault Loop Impedance Measurement in Low Voltage Network with Residual Current Devices. Electron. Electr. Eng. 2012, 122, 109-112.

9. Hadziefendic, N.; Kostic, N.; Trifunovic, J.; Kostic, M. Detection of Poor Contacts in Low-Voltage Electrical Installations. IEEE Trans. Comp. Pack. Man. Techn. 2019, 9, 129-137. [CrossRef]

10. Mitolo, M.; Liu, H. Touch Voltage Analysis in Low-Voltage Power Systems Studies. IEEE Trans. Ind. Applic. 2016, 52, 556-559. [CrossRef]

11. Mitolo, M.; Bajzek, T.J. New Generation Tester to Assess the Electrical Safety in Low-Voltage Distribution Systems. IEEE Trans. Ind. Applic. 2019, 55, 106-110. [CrossRef]

12. Czapp, S. Method of earth fault loop impedance measurement without nuisance tripping of RCDs in 3-phase low-voltage circuits. Metrol. Meas. Syst. 2019, 26, 217-227.

13. Eaton Industries (Austria) GmbH. xSpider Version 3.3, User's Manual; Eaton: Wien, Austria, 2019.

14. Megger. Earth Electrode and Earth Loop Impedance Testing. Theory and Applications. Available online: https://uk.megger.com/ support/technical-library/application-notes/earth-electrode-and-earth-loop-impedance-testing-t (accessed on 1 November 2020). 